\title{
AN IMPLICIT CONTROLLER FOR THE STEEL LEVEL REGULATION IN A VACUUM-BASED CONTINUOUS CASTING PROCESS
}

\author{
M. A. Barrón' \& J. González² \\ ${ }^{1}$ Departamento de Materiales, ${ }^{2}$ Departamento de Sistemas \\ Universidad Autónoma Metropolitana-Azcapotzalco \\ Apartado Postal 75-338, México, D.F., México
}

Received: July $3^{\text {rd }} 2002$ and accepted May $9^{\text {th }} 2003$

\begin{abstract}
A nonlinear mathematical model of a vacuum-based continuous casting process and an implicit nonlinear controller are developed. The aim of the controller is the regulation of the mold and tundish molten steel levels. In the proposed approach, the output error is designed to be asymptotically stable, and the current values of the control inputs are numerically determined using the Newton-Rapson iterative procedure. The dynamic performance of the closed-loop system is analyzed using computer simulations.
\end{abstract}

\section{RESUMEN}

En este trabajo se desarrollan un modelo matemático de un proceso de colada continua de acero mediante vacío y un controlador implícito no lineal. El objetivo del controlador es regular los niveles de acero fundido en el molde y el distribuidor. En el enfoque propuesto, el error de salida se diseña de modo que el sistema a lazo cerrado sea asintóticamente estable y los valores actuales de las entradas de control se determinan mediante el método iterativo de Newton-Raphson. El desempeño dinámico del controlador se analiza mediante simulaciones numéricas.

KEYWORDS: Discrete controller, Implicit control, Level control.

\section{INTRODUCTION}

Recently, a vacuum technique for handling the flow of molten steel in a continuous casting process has been proposed [1]. It uses a reduced pressure in the vacuum chamber of the tundish to regulate the inflow rate of molten steel to the mold. This technique improves the surface quality of the solid product, promotes the steel cleanliness due to an enhanced inclusion flotation in the tundish, and improves the flow patterns in the mold avoiding slag trapping and steel oxidizing [2]. During metal casting, the tundish and mold levels must be maintained constant to prevent molten steel overflows, mold emptying, or slag trapping.

On the other hand, the above vacuum-based continuous casting process constitutes a class of non-affine nonlinear systems. In these systems, the control inputs are not linear with respect to the time derivatives of states $[3,4]$. Therefore, conventional nonlinear control approaches, such as feedback linearization, can not be directly applied. Thus, it is important the development and implementation of novel control approaches and techniques to regulate this particular class of nonlinear systems. 
A powerful nonlinear control theory has been developed since the eighties which uses feedback linearization to synthesize controllers for affine nonlinear systems, however there are few reports about the application of this approach in non-affine systems of the type $\dot{x}=f(x)+\psi(x, u)$, where $\psi(x, u)$ is a nonlinear function. Among the above reports are the works of Ostojic [5] and Barron et al. [6]. Ostojic [5] employs recursive numerical approaches, such as Newton-Raphson and successive substitutions. Barron et al. [6] analyze the appropriateness of the control actions and correct those which are wrong by modifying the control law.

In this work, first a mathematical model of a vacuum-based continuous casting process is developed. Then, an implicit controller is proposed. To regulate the tundish and mold levels, the position of a slide-gate valve of the ladle and the vacuum chamber pressure of the tundish are utilized as control inputs. The current values of the control inputs are determined through the Newton-Raphson iterative procedure [7]. Finally, the dynamic performance of the closed-loop system is illustrated by means of numerical simulations.

\section{MATHEMATICAL MODEL}

\subsection{Liquid steel levels}

The mathematical model which describes the dynamic behavior of the liquid steel levels in a vacuum-based continuous casting process (see Figure 1) is developed in this section using mass balances. Molten steel flows by gravity from the ladle into the tundish through a slide-gate valve. The flow area of the ladle slide-gate valve is adjusted by moving a computerized hydraulic arm. The automated arm pushes a holed mobile plate on a holed fixed plate. Besides, a nozzle with constant flow area is located at the tundish bottom. The flow-rate of molten steel into the mold is regulated by manipulating the pressure in the vacuum chamber of the tundish. In the mold, whose water-cooled walls are made of copper plates, molten steel is frozen below its solidification temperature and, consequently, a thin shell of solid steel is formed. Then, extracting rolls pull down the partially solidified slab. Water sprays carry out the task of completely solidify the liquid core of the slab. The solid slab is extracted with a certain speed, namely casting speed. Finally, the slab is transferred to a cut-off machine which cuts the product into ordered lengths [8].

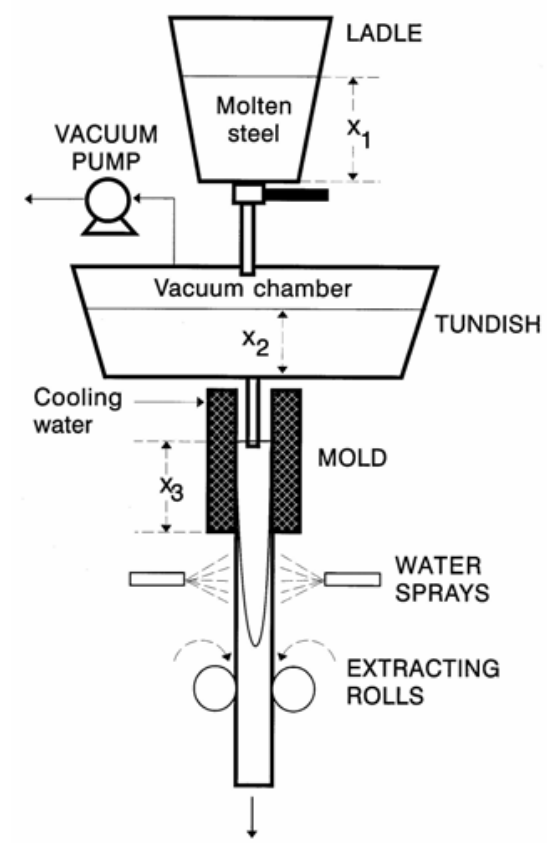

Figure 1. The vacuum-based continuous casting process 
A mass balance in the ladle yields $A_{1} \dot{x}_{1}=Q_{1 \text { in }}-Q_{1 \text { out }}$, where $A_{1}$ is the cross sectional area of the ladle, $x_{1}$ is the ladle molten steel level, $\boldsymbol{x}_{1}$ is the time derivative of $x_{1}$, and $\mathrm{Q}_{\text {in }}$ and $\mathrm{Q}_{\text {iout }}$ are the inflow and outflow rate of molten steel, respectively. In the ladle there is no inflow of molten steel, so that $\mathrm{Q}_{1 \mathrm{in}}=0$. For molten steel contained in an open vessel such as the ladle, the outflow rate through the nozzle is determined in this way: $Q_{1 \text { out }}=C_{D 1} A_{1 n}(s) \sqrt{2 g x_{1}}$, where $A_{1 n}$ is the current flow area of the ladle slide-gate valve, which depends on the arm position, $s$. Besides, $C_{D^{1}}$ is the discharge coefficient of the valve, and $g$ is the gravity constant. Manipulating the above equations, the following expression for the rate of change of the ladle level is obtained:

$$
\dot{x}_{1}=-\left(\frac{1}{A_{1}}\right) C_{D 1} A_{1 n}(s) \sqrt{2 g x_{1}}
$$

On the other hand, a trigonometric analysis yields this expression, which relates the current flow area of the slide-gate valve with the arm position:

$$
A_{1 n}(s)=\left(\frac{D^{2}}{2}\right) \cos ^{-1}\left(\frac{D-s}{D}\right)-\left(\frac{D-s}{2}\right) \sqrt{D^{2}-(D-s)^{2}}
$$

where $\mathrm{D}$ is hole diameter of the slide-gate valve.

From the last expression one can corroborate that when $s=0$ the slide-gate valve is fully closed, i.e. $A_{\ln }(0)=0$, and therefore the current flow area is null. On the other hand, when $s=D$ the slide-gate is fully open, i.e. $A_{n n}(D)=\pi D^{2} / 4$, which corresponds to the maximum flow area. Commonly, the values of the arm position of the slide-gate valve are bounded by a minimum value, $s_{\min }$, and a maximum value, $s_{\max }$, therefore $s \in\left[s_{\min }, s_{\max }\right]$.

A mass balance in the tundish yields: $A_{2} \dot{x}_{2}=Q_{i n}-Q_{2 o u t}$, where $A_{2}$ is the tundish cross sectional area, $x_{2}$ is the tundish steel level, $\dot{x_{2}}$ is the time derivative of $x_{2}, Q_{2 i n}$ is the inflow rate of molten steel to the tundish, and $\mathrm{Q}_{2 \text { out }}$ is the outflow rate of steel from the tundish. In Figure 1 it is observed that the inflow rate to the tundish is equal to the outflow rate from the ladle, i.e. $\mathrm{Q}_{2 \text { in }}=\mathrm{Q}_{1 \text { out }}$. Besides, $\mathrm{Q}_{2 \text { out }}$ depends on the pressure in the vacuum chamber as follows ${ }^{9}[9]$ :

$$
Q_{2 o u t}=C_{D 2} A_{2 n} \sqrt{2 g\left(x_{2}-\frac{p_{a}-p}{\rho g}\right)},
$$

where $C_{D 2}$ is the discharge coefficient of the tundish nozzle, $A_{2 n}$ is the flow area of the tundish nozzle, $p$ is the pressure in the tundish vacuum chamber, $p_{a}$ is the atmospheric pressure, and $\rho$ is the density of molten steel.

In practice, the permissible values of the pressure in the vacuum chamber are bounded by the minimum pressure achievable through the vacuum pump, $\mathrm{p}_{\min }$, and the atmospheric pressure, $\mathrm{p}_{\mathrm{a}}$, therefore $\mathrm{p} \in\left[\mathrm{p}_{\min }, \mathrm{p}_{\mathrm{a}}\right]$. In accordance with the these remarks, the expression for the rate of change of the tundish level is:

$$
\dot{x_{2}}=\left(\frac{1}{A_{2}}\right)\left(C_{D 1} A_{n}(s) \sqrt{2 g x_{1}}-C_{D 2} A_{2 n} \sqrt{2 g}\left(x_{2}-\frac{p_{a}-p}{\rho g}\right)\right) .
$$


In the mold a mass balance yields: $A_{3} \dot{x}_{3}=Q_{3 i n}-Q_{3 o u t}$, where $A_{3}$ is the cross sectional area of the mold, $x_{3}$ is the mold steel level, $\dot{x}_{3}$ is the time derivative of $\mathrm{x}_{3}, \mathrm{Q}_{3 \text { in }}$ and $\mathrm{Q}_{3 \text { out }}$ are the inlet and outlet flow rates of the mold, respectively. On the other hand, $\mathrm{Q}_{3 \text { out }}$ depends on the casting speed $\mathrm{v}_{\mathrm{c}}$ in this way: $\mathrm{Q}_{3 \text { out }}=\mathrm{A}_{3} \mathrm{v}_{\mathrm{c}}$. Manipulating the above expressions, the rate of change of the mold level is given by:

$$
\dot{x}_{3}=\left(\frac{1}{A_{3}}\right) C_{D 2} A_{2 n} \sqrt{2 \mathrm{~g}\left(x_{2}-\frac{p_{a}-p}{\rho \mathrm{g}}\right)}-v_{c}
$$

In the last mathematical model, the molten steel levels are, by definition, non-negative. On the other hand, it can be easily verified that the arguments of the square root functions become always non-negative. Besides, the positive value of the square roots is considered.

\subsection{Effect of temperature on the liquid steel density}

In Eqs. (3)-(4) the density of liquid steel is involved, which depends on temperature. Given that the temperature of steel is continuously decreasing due to heat losses in the ladle and tundish, the density of steel is continuously changing too. This phenomenon must be considered in order to test the ability of the proposed controller to cope with it. In accordance with Chakraborty and Sahai [10], the density of steel (in $\mathrm{kg} \mathrm{m}^{-3}$ ) changes linearly with temperature in this way:

$$
\rho(T)=7010-0.883\left(T-T_{m p}\right)
$$

where $\mathrm{T}_{\mathrm{mp}}=1538^{\circ} \mathrm{C}$ is the melting point of iron.

These authors [10] also report that at industry the temperature of the tundish incoming stream decreases at a rate of $0.00833{ }^{\circ} \mathrm{C} \mathrm{s}^{-1}$ over the teeming period, and that the steel temperature drops by about $3{ }^{\circ} \mathrm{C}$ as it reaches the tundish outlet. Then, average steel temperature in the tundish and mold changes along the teeming period as follows:

$$
T(t)=T_{0}-0.00833 t-3
$$

where $T_{0}$ is the temperature of the liquid steel stream at the beginning of the teeming, and $t$ is the time in seconds.

\section{IMPLICIT CONTROLLER}

\subsection{Theoretical issues}

Feedback linearization is an approach for nonlinear control design which has caught the attention of researchers during the last two decades. However, it has been mostly applied to nonlinear systems described by a set of equations of the form $[3,4] \dot{x}=f(x)+\sum_{i=1}^{m} b_{i}(x) u_{i}$, where $x \in \mathfrak{R}^{n}$ is the vector of states, $\mathrm{f}(\mathrm{x})=\left[\mathrm{f}_{1}, \ldots, \mathrm{f}_{\mathrm{n}}\right]^{\mathrm{T}}$ and $\mathrm{b}_{\mathrm{i}}(\mathrm{x})=\left[\mathrm{b}_{\mathrm{i}_{\mathrm{i}}}, \ldots, \mathrm{b}_{\mathrm{n}_{\mathrm{i}}}\right]^{\mathrm{T}}$ are vectors of nonlinear functions, and $\mathrm{u}=\left[\mathrm{u}_{1}, \ldots, \mathrm{u}_{\mathrm{m}}\right]^{\mathrm{T}}$ is the control input vector.

In the above nonlinear systems, commonly named affine systems, there is a linear dependence between the control inputs and the state derivatives. However, there is a class of nonlinear systems, named non-affine systems, whose 
control inputs are not linear with respect to the state derivatives, i.e. $x=f(x)+\psi(x, u)$, where $\psi(x, u) \in \mathfrak{R}^{n}$ is a vector of nonlinear functions. The control output vector $y \in \mathfrak{R}^{m}$ for this system is given by $y=C x$, where $C \in \mathfrak{R}^{m \times n}$ is a constant matrix. In this work an implicit control approach is proposed. The dynamic behavior of the outputs errors is established, and then an implicit controller is synthesized. The values of the control inputs are numerically determined using an iterative procedure.

To establish the error dynamics for the nonlinear non-affine system described above, let us define an output error vector $\mathrm{e} \in \mathfrak{R}^{m}$ as $\mathrm{e}(\mathrm{t})=\mathrm{y}(\mathrm{t})-\mathrm{y}^{\mathrm{sp}}(\mathrm{t})$, where $\mathrm{y}^{\mathrm{sp}}(\mathrm{t})$ is the setpoint vector. The error dynamics is given by $\dot{e}=\dot{y}-\dot{y}^{s p}=C x-\dot{y}^{s p}=C(f(x)+\psi(x, u))-\dot{y}^{s p}$. Given that this work deals with a regulation problem, then $\dot{y^{s p}}=0$. Now, let us assume that the desired output error dynamics is linear asymptotically stable, i.e. $\dot{e}+G e=0$, where $G \in \mathfrak{R}^{m \times m}$ is the control gain matrix. If the control gain matrix $G$ is diagonal, then a decoupled control scheme results.

On the other hand, by combining the error dynamics expression with the desired output error dynamics, this expression is obtained: $-G e=C(f(x)+\psi(x, u))$. Considering an implicit form of the last equation, namely $F\left(t, x, u, y^{s p}\right)=G e+C(f(x)+\psi(x, u))=0$, the current value of the control input vector $u(t)$ can be numerically determined by solving $F\left(t, x, u(t), y^{s p}\right)=0$. In this work the Newton-Raphson method [7] is employed to obtain the control input vector:

$$
u^{k+1, \ell}=u^{k, \ell}-\left(J^{k, \ell}\right)^{-1} F^{k, \ell}
$$

where $u^{k, \ell}$ is the vector of control inputs at time $t^{\ell}$ and iteration $k, F^{k, \ell}=F\left(t^{\ell}, x^{\ell}, u^{k, \ell}, y^{s p}\right)$, and $J^{k, \ell}$ is the Jacobian of $F^{k, \ell}$ :

$$
J^{k, \ell}=\left[\begin{array}{ccc}
\left(\frac{\partial F_{1}}{\partial u_{1}}\right)_{k, \ell} & \cdots & \left(\frac{\partial F_{1}}{\partial u_{m}}\right)_{k, \ell} \\
\vdots & \ddots & \vdots \\
\left(\frac{\partial F_{m}}{\partial u_{1}}\right)_{k, \ell} & \cdots & \left(\frac{\partial F_{m}}{\partial u_{m}}\right)_{k, \ell}
\end{array}\right]
$$

This controller provides discrete values of the control inputs, then it is discrete in nature. A zero order hold is assumed for the control inputs, i.e. the control inputs remain constant in the time interval $\left[t^{\ell}, t^{\ell+1}\right]$. If $J^{k, \ell}$ is diagonal, then Eq. (7) yields a decoupled controller. On the contrary, if $J^{k, \ell}$ is not diagonal, then at least one of the multivariable interactions must be addressed.

The controller given by Eq. (7) is realizable if and only if $J^{k, \ell}$ is invertible. Besides, the controller is convergent whenever the following two conditions are verified:

i) $\lim _{k \rightarrow \infty}\left\|u^{k+1, \ell}-u^{k, \ell}\right\|_{q}=0$ where $\|\bullet\|_{q}$ is the associated q-norm of $\bullet$. The above condition is equivalent to[7]:

$$
\left\|I-\frac{\partial}{\partial u}\left(\left(J^{k, \ell}\right)^{-1} F^{k, \ell}\right)\right\|_{q}<1 \quad \forall \quad t^{\ell}, x^{\ell}, u^{k, \ell}, y^{s p}
$$


where, I, is the identity matrix.

(ii) The control inputs must remain bounded [5]. In this way the input constraint issue is addressed in a natural way in the controller synthesis.

Inequality given by Eq. (9) is the multivariable representation of the well-known fixed-point convergence condition [7]. For the sake of simplicity, the closed-loop stability proof can be found in Ostojic [5].

\subsection{IMPLICIT CONTROLLER OF THE MOLD AND TUNDISH LEVELS}

The pressure in the vacuum chamber of the tundish and the arm position of the ladle slide-gate valve are employed to regulate the mold and tundish levels. Thus, a coupled two-input two-output nonlinear system arises where $y=\left[\begin{array}{ll}x_{2} & x_{3}\end{array}\right]^{T}$ is the control output vector and $\mathrm{u}=\left[\mathrm{u}_{1} \mathrm{u}_{2}\right]^{\mathrm{T}}=[\mathrm{s} \mathrm{p}]^{\mathrm{T}}$ is the control input vector. Since Eqs. (3) and (4) exhibit nonlinear dependences between the mold level time derivative and the pressure in the vacuum chamber, and between the tundish level time derivative and the arm position of the slide-gate valve, an implicit approach is required to synthesize the controller.

The continuous casting mathematical model can be expressed in this way: $\dot{x}=f(x)+\psi(x, u)$, where $\psi(x, u) \in \mathfrak{R}^{n}$ is a vector of nonlinear functions.

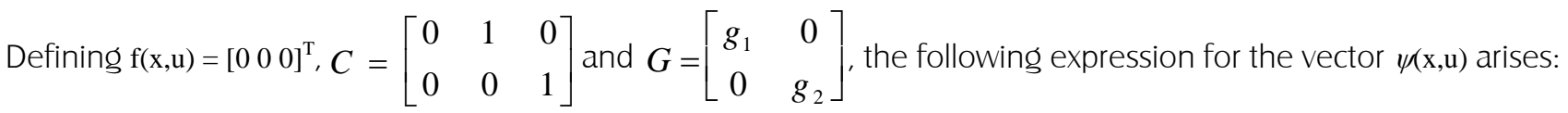

$$
\psi(x, u)=\left[\begin{array}{c}
-\left(\frac{1}{A_{1}}\right) C_{D 1} A_{1 n}\left(u_{1}\right) \sqrt{2 \mathrm{~g} x_{1}} \\
\left(\frac{1}{A_{2}}\right)\left(C_{D 1} A_{1 n}\left(u_{1}\right) \sqrt{2 \mathrm{~g} x_{1}}-C_{D 2} A_{2 n} \sqrt{2 \mathrm{~g}\left(x_{2}-\frac{\left.p_{a}-u_{2}\right)}{\rho \mathrm{g}}\right)}\right) \\
\left(\left(\frac{1}{A_{3}}\right) C_{D 2} A_{2 n} \sqrt{\left.2 \mathrm{~g}\left(x_{2}-\frac{p_{a}-u_{2}}{\rho \mathrm{g}}\right)\right)-v_{c}}\right.
\end{array}\right] .
$$

Due to the control gain. matrix $G$ is forced to be diagonal, the following multivariable implicit controller results:

$$
F_{1}\left(t, x, u, y^{s p}\right)=g_{1} e_{1}+\psi_{2}(x, u) \text { and } F_{2}\left(t, x, u, y^{s p}\right)=g_{2} e_{2}+\psi_{3}(x, u)
$$

A multivariable approach is needed despite the difference in the characteristic times of the mold and the tundish, given that an approach of this kind guarantees good disturbances rejection. The above continuous implicit controller is used to obtain a discrete implicit controller. The values of the discrete control inputs are numerically determined by solving the previous equations for $F_{1}^{k, \ell}\left(t^{\ell}, x^{\ell}, u^{k, \ell}, y^{s p}\right)=0$ and $F_{2}^{k, \ell}\left(t^{\ell}, x^{\ell}, u^{k, \ell}, y^{s p}\right)=0$ by employing the Newton-Raphson iterative procedure. In accordance with Eq. (7), the resulting iterative controller is expressed in this way: 


$$
\begin{gathered}
u_{1}^{k+1, \ell}=u_{1}^{k, \ell}-\left(\frac{\left(g_{1} e_{1}^{k, \ell}+\psi_{2}^{k, \ell}\right)\left(\frac{\partial \psi_{3}}{\partial u_{2}}\right)_{k, \ell}+\left(g_{2} e_{2}^{k, \ell}+\psi_{3}^{k, \ell}\right)\left(\frac{\partial \psi_{2}}{\partial u_{1}}\right)_{k, \ell}}{\left(\frac{\partial \psi_{2}}{\partial u_{1}}\right)_{k, \ell}\left(\frac{\partial \psi_{3}}{\partial u_{2}}\right)_{k, \ell}}\right) \\
u_{2}^{k+1, \ell}=u_{2}^{k, \ell}-\left(\frac{g_{2} e_{2}^{k, \ell}+\psi_{3}^{k, \ell}}{\left(\frac{\partial \psi_{3}}{\partial u_{2}}\right)_{k, \ell}}\right)
\end{gathered}
$$

The controller defined by Eqs. (11) and (12) is realizable if and only if $\frac{\partial \psi_{2}}{\partial u_{1}} \frac{\partial \psi_{3}}{\partial u_{2}} \neq 0$ and $\frac{\partial \psi_{3}}{\partial u_{2}} \neq 0$. It can be verified that these conditions holds whenever $\mathrm{u}_{1}>0$ and $\frac{p_{a}-p_{\max }}{\rho g} \leq x_{2} \leq \frac{p_{a}-p_{\min }}{\rho g}$.

\section{NUMERICAL SIMULATIONS}

In order to test the dynamic performance of the proposed controller, computer simulations were carried out using the following parameter values: $\mathrm{A}_{1}=6.0 \mathrm{~m}^{2}, \mathrm{~A}_{2}=3.0 \mathrm{~m}^{2}, \mathrm{~A}_{3}=0.20 \mathrm{~m}^{2}, \mathrm{~A}_{2 \mathrm{n}}=0.00280 \mathrm{~m}^{2}, \mathrm{C}_{\mathrm{D} 1}=0.96$ (dimensionless), $\mathrm{C}_{\mathrm{D} 2}=0.96$, $\mathrm{D}=0.080 \mathrm{~m}, \mathrm{v}_{\mathrm{c}}=0.0333 \mathrm{~ms}^{-1}, \mathrm{p}_{\max }=0.10 \mathrm{MPa}, \mathrm{P}_{\min }=0.040 \mathrm{MPa}, \mathrm{s}_{\max }=0.080 \mathrm{~m}, \mathrm{~s}_{\min }=0.010 \mathrm{~m}$. The considered initial conditions were $\mathrm{x}_{1}(0)=2.0 \mathrm{~m}, \mathrm{x}_{2}(0)=1.2 \mathrm{~m}, \mathrm{x}_{3}(0)=0.1 \mathrm{~m}, \mathrm{~T}_{0}=1565^{\circ} \mathrm{C}$. In the computer simulations the steel density was continuously updated using Eqs. (5) and (6). The chosen values of the control gains were $g_{1}=0.1$ and $g_{2}=1.0$. These values come from the fact that the characteristic time of the tundish is considerably greater than that of the mold, then $g_{2}>g_{1}$. Besides, the setpoints values were $y_{1}^{s p}=1.0 m$ and $y_{2}^{s p}=0.6 m$.

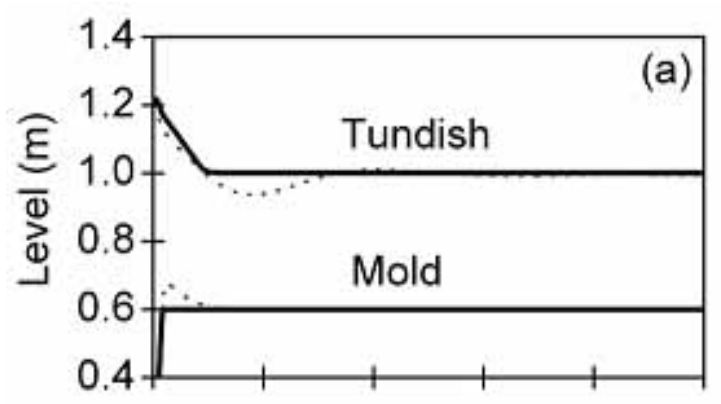

(a) Molten steel levels

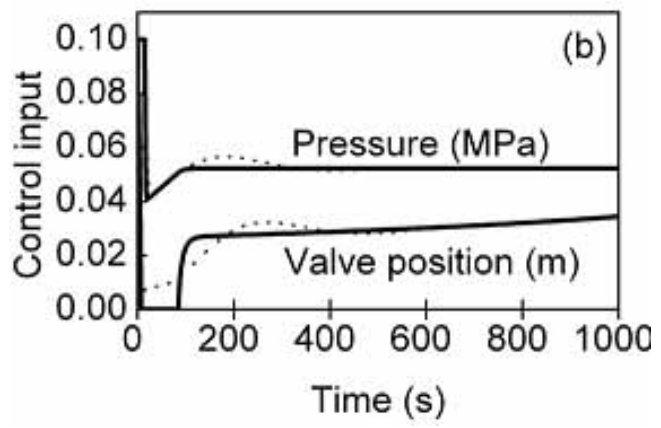

(b) Corresponding control inputs. Proposed controller, .....PID controller.

Figure 2. Closed-loop dynamic performance for a typical regulation problem 
The proposed controller was compared with a conventional proportional-integral-derivative (PID) controller. The PID controller was tuned in accordance with the tuning rules recently proposed by Visioli" in order to obtain an optimal load disturbance rejection. Figures 2(a) and 2(b) show the simulation results for a typical regulation problem. In Figure 2(a) one can see that the proposed controller drives the mold level to the set point in approximately $15 \mathrm{~s}$, while the tundish level reaches the set point in $90 \mathrm{~s}$. Figure 2(b) shows the corresponding control inputs. Since the control inputs are bounded, they exhibit transient saturation. Because at time $t=0$ the mold level is below the setpoint, the controller rises the pressure in the vacuum chamber up to the atmospheric pressure, i.e. the pressure upper bound. This action allows more molten steel flows into the mold. On the other hand, since at time $t=0$ the tundish level is above the set point, the controller closes the ladle slide-valve to prevent that molten steel flows into the tundish. The controller opens the slide-gate valve once the setpoint has been reached. The dynamic performance of the aforementioned PID controller is also shown in Figures 2(a) and 2(b) for the same regulation problem. PID controller exhibits significant overshoots for short times, which are unacceptable in industrial practice given that a catastrophic spilling out of the mold may arise. Nevertheless, for long times the dynamic behaviors of both controllers are identical.

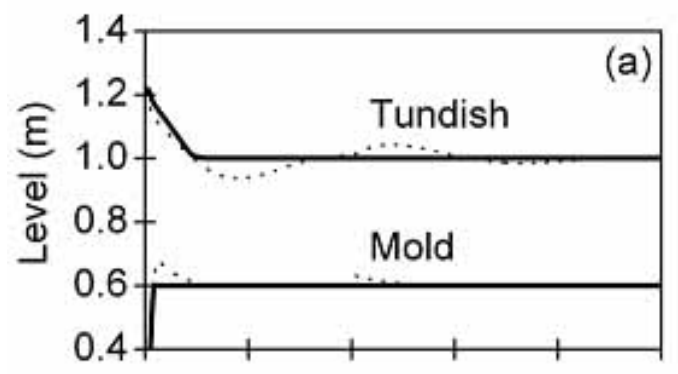

(a) Molten steel levels

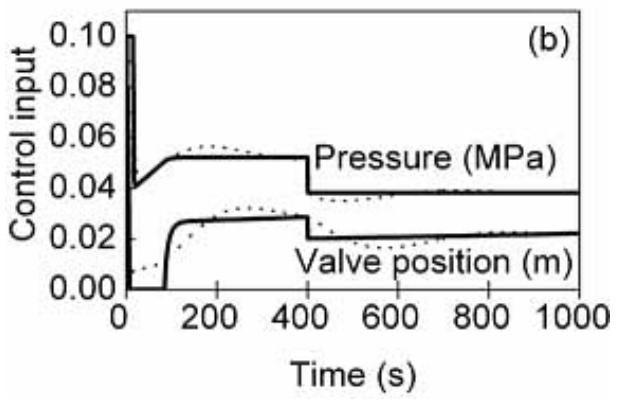

(b) Corresponding control inputs. ___ Proposed controller, .....PID controller.

Figure 3. Closed-loop dynamic performance for a step disturbance in casting speed, from $0.033 \mathrm{~ms}^{-1}$ to $0.020 \mathrm{~ms}^{-1}$ at $t=400 \mathrm{~s}$

In Figures 3(a) and 3(b), the casting speed is suddenly decreased from $0.033 \mathrm{~ms}^{-1}$ to $0.020 \mathrm{~ms}^{-1}$ at time $\mathrm{t}=400 \mathrm{~s}$. It is observed the complete rejection of the casting speed perturbation with moderate control actions of the proposed controller. On the contrary, the PID controller carries out severe control actions in order to restore the mold and tundish levels to the setpoints. However, these control actions cause unpleasant transient overshoots in the control outputs.

To test the robustness of the proposed control scheme, the control law was evaluated assuming a constant density of steel while the steel density in the plant was changing with time and temperature. Numerical simulations showed that the maximum difference between the control outputs considering both constant and variable steel density in the controller evaluation is around $0.1 \%$, which represents a negligible change in the dynamic performance. This is due to 
the fact that, in accordance with Eqs. (5)-(6), for a typical teeming period of $3000 \mathrm{~s}$ the steel temperature only decreases $25^{\circ} \mathrm{C}^{10}$, which corresponds to a non-significant change in density (of around $0.3 \%$ ).

\section{CONCLUSIONS}

In this work, a mathematical model for a vacuum-based continuous casting process and a nonlinear implicit controller has been developed. Once a dynamic response for the control output is established, a discrete implicit controller is obtained, which is solved through a numerical iterative procedure. Computer simulations show that the dynamic performance of the proposed controller is more appropriate than that of a PID conventional controller

\section{REFERENCES}

[1] Stamp, D.W. "Application of Vacuum Technology to the Tundish". Report EUR 17844 EN, European Commission, United Kingdom, 1998.

[2] Wolf, M. "Responding to the Challenge of High Speed Slab Casting". Stee/ Times Int., May/June, 1994, pp. 4.

[3] Slotine, J.J., Li, W. Applied Nonlinear Control. New Jersey: Prentice-Hall, pp 461, 1991.

[4] Isidori, A. Nonlinear Control Systems. New York: Springer-Verlag, 1995, pp 147-161.

[5] Ostojic, M. "Numerical Approach to Nonlinear Control Design". Trans. of the ASME, Vol. 118, 1996, pp. 332337.

[6] Barrón, M.A., Aguilar, R., González, J. "Regulation of the Mold Level through Vacuum in a Steel Continuous Casting Process". IEE Proc.-Control Theory and Applications, Vol. 147, 2000, pp. 416-420.

[7] Burden, R.L., Faires, J.D. Numerical Analysis. New York: PWS Publishing, 1993, pp. 126-148.

[8] Kozak, B., Dzierzawski, J. Continuous Casting of Steel: Basic Principles. Washington: AISI Learning Center, 2002, pp. 9.

[9] Geiger, G.H., Poirier, D.R. Transport Phenomena in Metallurgy. Menlo Park: Addison-Wesley Publishing, 1973, pp. 136.

[10] Chakraborty, S., Sahai, Y. "Effect of Varying Ladle Stream Temperature on the Melt Flow and Heat Transfer in Continuous Casting Tundishes". ISIJ Int., Vol. 31, 1991, pp. 960-967.

[11] Visioli, A. "Optimal Tuning of PID Controllers for Integral and Unstable Processes". IEE Proc.-Control Theory and Applications, Vol. 148, 2001, pp. 180-184.

Authors Biography

\section{Miguel Angel Barrón Meza}

Received the B.Sc. degree in chemical-metallurgical engineering from Universidad Nacional Autónoma de México, the M.Sc. degree in chemical engineering from Universidad Autónoma Metropolitana Iztapalapa, and the PhD degree in materials science from Instituto Politécnico Nacional in 1981, 1992 and 1997, respectively. His research interests are in simulation and control of metallurgical processes. He is currently professor at the Materials Department of Universidad Autónoma Metropolitana Azcapotzalco. Besides, he is a member of the National System of Researchers since 1998.

\section{Jesus González Trejo}

Is a Chemical Engineer from Universidad Autónoma Metropolitana Azcapotzalco (UAM) (1989), M.Sc. in chemical engineering from UAM - Iztapalapa (1994), and Ph.D. from UAM - Iztapalapa (1998). Since 1992 he has been professor in the Systems Department at the Universidad Autónoma Metropolitana - Azcapotzalco, where currently he is in charge of the Computational Systems Area. Since 1997 is member of the National System of Researchers. 